\title{
About the Role of Fe-Ions in the Formation of Magnetocaloric Effect in $\mathrm{Ho}\left(\mathrm{Co}_{1-x} \mathrm{Fe}_{x}\right)_{2}$ Compounds
}

\author{
M.S. Anikin*, E.N. Tarasov, N.V. Kudrevatykh, V.H. Osadchenko and A.V. Zinin \\ Ural Federal University, Mira str. 19, 620002 Ekaterinburg, Russia
}

\begin{abstract}
A study of crystalline structure, magnetic and magnetocaloric properties of $\mathrm{Ho}\left(\mathrm{Co}_{1-x} \mathrm{Fe}_{x}\right)_{2}(x=0.09,0.12)$ intermetallic compounds has been undertaken. Phase composition was controlled by X-ray diffraction analysis. Magnetic properties were measured within the temperature range $4.2-350 \mathrm{~K}$ in magnetic fields up to $7 \mathrm{~T}$. Magnetic ordering temperatures corresponding to paramagnetic-ferrimagnetic phase transitions were found to be $199 \mathrm{~K}$ and $258 \mathrm{~K}$ respectively. Temperature dependences of heat capacity for these compounds have been inferred for the temperature interval 77-340 K. Comparison of magnetocaloric effect (MCE) values determined by direct measurement and by calculation was carried out as well. It was found that significant MCE peak broadening occurs for higher iron concentration in the compound.
\end{abstract}

DOI: $10.12693 /$ APhysPolA.127.635

PACS: $75.30 . \mathrm{Sg}, 75.50 . \mathrm{Gg}$

\section{Introduction}

$\mathrm{RT}_{2}$ type intermetallic compounds (where $\mathrm{R}$ - rare earth, $\mathrm{T}=\mathrm{Fe}, \mathrm{Co}, \mathrm{Ni}$ ) or Laves phases with cubic crystalline structure have been studied intensively for more than 3 decades, primarily because of the giant magnetostriction values observed for the iron-based alloys [1].

Some $\mathrm{RT}_{2}$ alloys based on Co, along with the magnetostrictive effect, demonstrate the significant magnetocaloric effect (MCE) near the Curie temperature $\left(T_{\mathrm{C}}\right)$, which is applicable for magnetic refrigeration technology [2]. Early MCE studies on RCo compounds by direct measurements were carried out on the samples of binary $\mathrm{HoCo}_{2}$ alloy [3].

Later, many authors [4-8] have been carried out indirect $\mathrm{MCE}$ estimations on $\mathrm{RCo}_{2}$ compounds using isotherms of magnetization curves and specific heat data.

The $\mathrm{RT}_{2}$ type intermetallic alloys are ferrimagnets with antiparallel orientation of $\mathrm{R}$ and $\mathrm{T}$ magnetic moments in case of heavy $R$. The magnetic behavior and magnetocaloric properties of these compounds are determined by competitive exchange interactions within subsystem (rare earth or 3d-metal) as well as between $R$ and T subsystems.

Recently, the study of $\mathrm{Ho}\left(\mathrm{Ni}_{1-x} \mathrm{Fe}_{x}\right)_{2}$ quasibinary system revealed that the nickel substitution by iron leads to abnormal MCE [9]. This anomaly manifested as MCE presence in much wider temperature range, contrary to the many known magnetocaloric materials. Later, a similar MCE behavior was observed in $\mathrm{Tb}\left(\mathrm{Ni}_{1-x} \mathrm{Fe}_{x}\right)_{2}$ [10] and $\operatorname{Er}\left(\mathrm{Co}_{1-x} \mathrm{Fe}_{x}\right)_{2}$ [11] compounds. Authors [12], investigating structure and magnetothermal properties of the $\mathrm{Tb}\left(\mathrm{Co}_{1-x} \mathrm{Fe}_{x}\right)_{2}$ system also found a significant magnetic entropy temperature range broadening in the

*corresponding author; e-mail: maksim.anikin@urfu.ru
$\mathrm{TbCo}_{0.9} \mathrm{Fe}_{0.1}$ compound compared with that in $\mathrm{TbCo}_{2}$. The neutron diffraction studies carried out in wide temperature range indicated existence of the structural phase transition (from rhombohedral to cubic with decreasing temperature) associated with the magnetic phase transition and broadening of the transition temperature interval when $\mathrm{Fe}$ is added.

These results prompted us to undertake the study of structural, magnetic and magneto-thermal properties of alloys similar to mentioned above - $\mathrm{Ho}\left(\mathrm{Co}_{1-x} \mathrm{Fe}_{x}\right)_{2}$ system with low Fe content $(x=0.09,0.12)$, which have not been investigated considered in literature from such point of view.

\section{Experimental details}

$\mathrm{Ho}\left(\mathrm{Co}_{1-x} \mathrm{Fe}_{x}\right)_{2}$ alloys $(x=0.09,0.12)$ were melted in induction furnace using a quartz crucible with an argon protective atmosphere. A homogenizing annealing of alloys was made in a vacuum furnace at $1220 \mathrm{~K}$ for six hours. Powders of the alloy were obtained by mechanical milling in a mortar with the 200-500 $\mu$ m fraction sieved. Phase composition control and crystalline structure studies were carried out by means of X-ray diffraction technique (diffractometer Bruker D8 Advance) with $\mathrm{Cu} K_{\alpha}$-radiation source. For X-ray diffraction patterns analysis FullProf v.2.05 software was used.

Magnetic phase analysis and magnetization curves measurements were made using SQUID-magnetometer MPMS-XL-7 EC (Quantum Design) in the temperature range from $4.2 \mathrm{~K}$ to $350 \mathrm{~K}$ in magnetic field up to $7 \mathrm{~T}$. Heat capacity was measured at zero magnetic field in the temperature range from $77 \mathrm{~K}$ to $340 \mathrm{~K}$.

Direct measurement of the $\Delta T$-effect was carried out with the help of a proprietary experimental apparatus in the magnetic field with $0.46 \mathrm{~T}$ magnetic field applied. To exclude the displacement of powder particles under study in the process of measurement, these were yielded into tablets, by mixing powders with epoxy adhesive and 
pressing. To account the influence of epoxy adhesive on the MCE, in a similar way the reference sample of $\mathrm{Gd}$ metal with the known value of the MCE for the choosen magnetic field was made [13]. A copper-constantan thermocouple was inserted into this sample. The signal from it was sent to a DC millivoltmeter, and from there to a computer.

\section{Results and discussion}

Analysis of the room temperature X-ray diffraction data showed that all samples within the study were almost single-phase. The 1:2 composition phase had a cubic structure of $\mathrm{MgCu}_{2}$ type with $F d 3 m$ space group. Its crystal lattice parameter $(a)$ has been determined (Table).

Samples were confirmed to contain only 1:2-phase by thermomagnetic analysis performed in the external magnetic field $(H)$ of $0.5 \mathrm{~T}$ (Fig. 1). Specific magnetization values corresponding to the magnetic field $\mu_{0} H=7 \mathrm{~T}$ $\left(M_{S}\right)$ at $4.2 \mathrm{~K}$ and the magnetic moment per formula unit $\left(M_{F U}\right)$ were calculated from $M_{S}$ values (in Bohr magneton $\left.-\mu_{\mathrm{B}}\right)$, which are shown in Table. Temperatures of magnetic transitions for different samples (Table) were determined in the position of the first derivative's $(\mathrm{d} M / \mathrm{d} T)$ peaks on the temperature axis, taken from the specific magnetization temperature dependencies $(M(T))$ in the magnetic field, with induction of $0.01 \mathrm{~T}$.

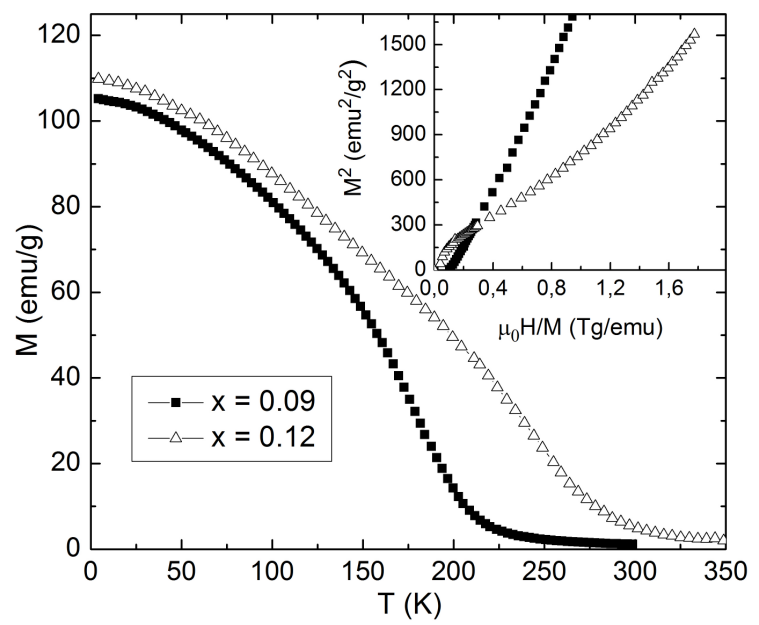

Fig. 1. Temperature dependencies of $\mathrm{Ho}\left(\mathrm{Co}_{1-x} \mathrm{Fe}_{x}\right)_{2}$ compounds magnetization measured in the magnetic field $\Delta \mu_{0} H=0.5 \mathrm{~T}$. Arrot curves for these compounds at corresponding Curie temperatures are shown in inset.

Type of the magnetic phase transition was determined using magnetic criterion proposed by Banerjee [14]. According to that, a positive value of the tangent angle to the Arrot isotherms at any point in the ferromagnetic state indicates the second order magnetic phase transition. Thus, based on the analysis of the experimental data (inset in Fig. 1) it can be argued that the phase transition in these compounds is a second order one.
TABLE

Crystal lattice parameters $(\boldsymbol{a})$, magnetization values in the magnetic field of $7 \mathrm{~T}\left(M_{S}\right)$, magnetic moment of formulae unit in $7 \mathrm{~T}\left(M_{F U}\right)$, and magnetic transition temperatures $\left(T_{\mathrm{C}}\right)$, for $\mathrm{Ho}\left(\mathrm{Co}_{1-x} \mathrm{Fe}_{x}\right)_{2}$ compounds on $\mathrm{Fe}$ concentration $(x)$

\begin{tabular}{c|c|c|c|c}
\hline \hline$x$ & $\begin{array}{c}a \\
{[\AA]}\end{array}$ & $\begin{array}{c}M_{S} \\
{\left[\mathrm{Am}^{2} / \mathrm{kg}\right]}\end{array}$ & $\begin{array}{c}M_{F U}\left[\mu_{\mathrm{B}} \text { per }\right. \\
\text { formula unit }]\end{array}$ & $\begin{array}{c}T_{\mathrm{C}} \\
{[\mathrm{K}]}\end{array}$ \\
\hline 0.09 & 7.1877 & 140.4 & 7.10 & 199 \\
0.12 & 7.1908 & 137.5 & 6.95 & 258
\end{tabular}

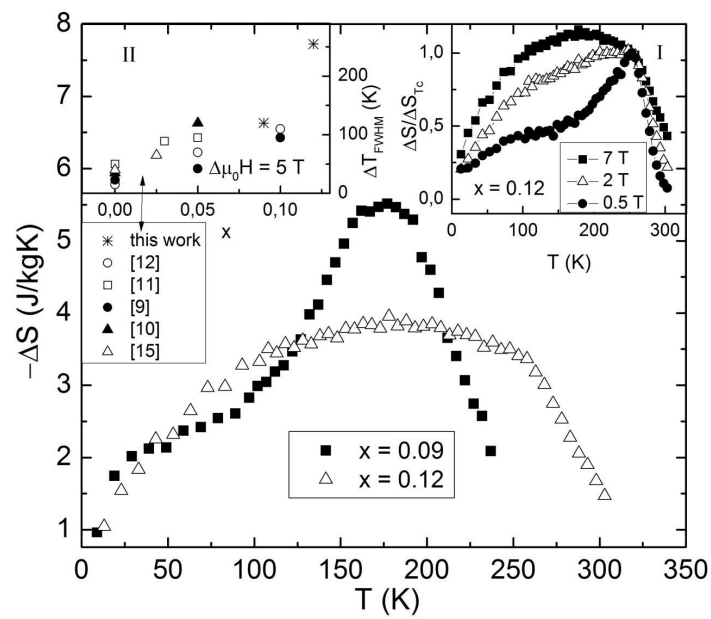

Fig. 2. Temperature dependencies of change of magnetic entropy $(\Delta S(T))$ in $\mathrm{Ho}\left(\mathrm{Co}_{1-x} \mathrm{Fe}_{x}\right)_{2}$ intermetallic compounds. Inset I $-\Delta S / \Delta S_{T_{c}}(T)$, were $\Delta S_{T_{c}}$ is $\Delta S$ at $T_{\mathrm{C}}$, for $\mathrm{Ho}\left(\mathrm{Co}_{0.88} \mathrm{Fe}_{0.12}\right)_{2}$ in different magnetic fields. Inset II $-\Delta T_{\mathrm{FWHM}}$ dependence on the iron concentration $(x)$ for $\mathrm{R}\left(\mathrm{M}_{1-x} \mathrm{Fe}_{x}\right)_{2}$ compounds.

For the calculation of isothermal entropy change $(\Delta S)$, which can be made using formulae (1) $[12,13]$, the samples magnetization field dependencies in the external magnetic fields $(0-7) \mathrm{T}$ in the wide temperature range with a step of $5-10 \mathrm{~K}$ were performed

$$
\Delta S(H, T)=\sum_{i} \frac{M_{i+1}\left(T_{i+1}, H\right)-M_{i}\left(T_{i}, H\right)}{T_{i+1}-T_{i}} \Delta H .
$$

Figure 2 shows the calculated values of $\Delta S$ data for the change of magnetic field $\Delta \mu_{0} H=7 \mathrm{~T}$. The figure shows that with iron concentration increasing, value $\Delta T_{\mathrm{FWHM}}$, characterizing the difference between higher and lower temperatures at half maximum of the $-\Delta S(T)$ peak, increases. Similar trend of $\Delta T_{\mathrm{FWHM}}$ increasing with magnetic field is observed for all $\mathrm{Ho}\left(\mathrm{Co}_{1-x} \mathrm{Fe}_{x}\right)_{2}$ samples. $\Delta S / \Delta S_{T_{c}}(T)$, where $\Delta S_{T_{c}}$ is $\Delta S$ at $T_{\mathrm{C}}$ for the sample with $x=0.12$ at various magnetic fields is shown in the inset I of Fig. 2. The inset II shows the values of $\Delta T_{\mathrm{FWHM}}$ for $\mathrm{R}\left(\mathrm{M}_{1-x} \mathrm{Fe}_{x}\right)_{2}$ compounds, where $\mathrm{M}=\mathrm{Co}$ or Ni. Data have been taken from the papers $[9-12,15]$ and from the present stady. The figure shows that for all $\mathrm{R}\left(\mathrm{M}_{1-x} \mathrm{Fe}_{x}\right)_{2}$ compounds with low $\mathrm{Ni}$ or Co substitutions by $\mathrm{Fe}$, a significant increase of $\Delta S(T)$ peak width is observed. For sample with $x=0.12 \Delta T_{\mathrm{FWHM}}=255 \mathrm{~K}$. Availability of ferromagnets with MCE in the wide temperature range 
is essential for potential use in magnetic refrigerants.

Figure 3 shows the temperature dependence of the magnetocaloric effect $\Delta T$ in $\mathrm{Ho}\left(\mathrm{Co}_{1-x} \mathrm{Fe}_{x}\right)_{2}$ compounds at various magnetic fields. For calculation of MCE values $\left(\Delta T_{\text {calc }}\right)$, the following formulae were used [13]:

$$
\Delta T_{\text {calc }}(T)=-\frac{T}{C_{P, H}(T)} \Delta S_{H}(T),
$$

where $C_{P, H}$ is the heat capacity of the sample material at the DC magnetic field, $\Delta S_{H}$ is the change of magnetic entropy part. Because of the absence of data on the temperature dependences of heat capacity for the DC magnetic field of $0.5 \mathrm{~T}$, the calculation of $\Delta T_{\text {calc }}$ was performed using the value of $C_{P, H}$ under $\mu_{0} H=0$ (inset Fig. 3). For comparison, in this figure values of $\Delta T(T)$ measured by direct method ( $\left.\Delta T_{\text {direct way }}\right)$ are shown. It can be concluded that the calculated values are close to those obtained by direct measurements. Differences between calculated and measured $\Delta T$-effect values may appear due to not taking into account the magnetic contribution to the specific heat.

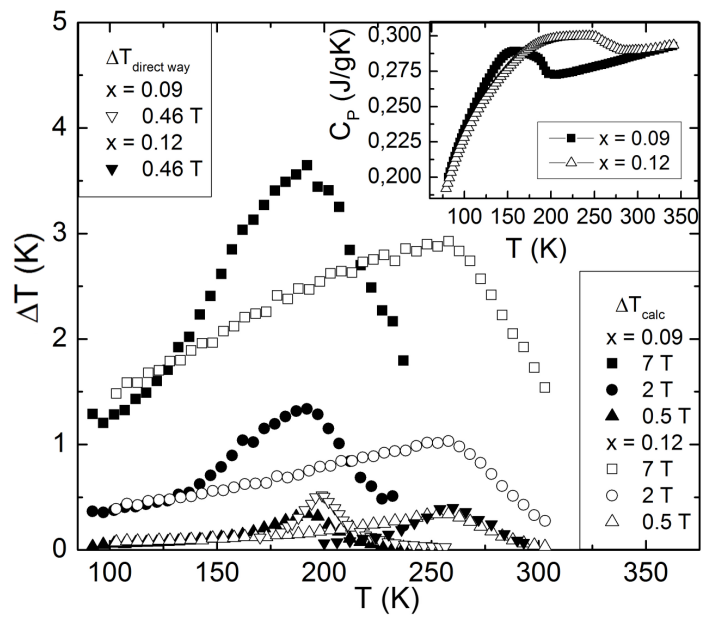

Fig. 3. Temperature dependences of $\Delta T$-effect values in $\mathrm{Ho}\left(\mathrm{Co}_{1-x} \mathrm{Fe}_{x}\right)_{2}$ compounds at various magnetic fields. Temperature dependencies of heat capacity $C_{p}$ of $\mathrm{Ho}\left(\mathrm{Co}_{1-x} \mathrm{Fe}_{x}\right)_{2}$ compounds at "zero" external magnetic field is shown in the inset.

To give more detailed magnetocaloric characteristics of the studied compounds, a comparison of their relative cooling capacity (RCP) [12] with the RCP of the similar compound was made:

$$
\mathrm{RCP}=-\int_{T_{1}}^{T_{2}} \Delta S(T) \mathrm{d} T,
$$

where $T_{1}$ and $T_{2}$ are the lowest and the highest temperatures on the $T$-axis, corresponding to half-height maximum of $\Delta S(T)$ dependence. RCP value of the $\mathrm{Ho}\left(\mathrm{Co}_{0.88} \mathrm{Fe}_{0.12}\right)_{2}$ compound in magnetic field of $5 \mathrm{~T}$ is about $612 \mathrm{~J} / \mathrm{kg}$, which is significantly higher than for the $\mathrm{Tb}\left(\mathrm{Co}_{0.97} \mathrm{Fe}_{0.03}\right)_{2}$ compound, where $\mathrm{RCP}=299 \mathrm{~J} / \mathrm{kg}$ $\left(\Delta \mu_{0} H=5 \mathrm{~T}\right)[12]$.
A significant increase in $\Delta S(T)$ peak width observed for $\mathrm{Ho}\left(\mathrm{Ni}_{1-x} \mathrm{Fe}_{x}\right)_{2}, \mathrm{~Tb}\left(\mathrm{Ni}_{1-x} \mathrm{Fe}_{x}\right)_{2}$, and $\mathrm{Tb}\left(\mathrm{Co}_{1-x} \mathrm{Fe}_{x}\right)_{2}$ compounds according to the authors $[9,10,12]$ may be due to both randomization of rare-earth magnetic moments orientations in the $\mathrm{R}$ sublattice and crystal structure transition in the mentioned temperature range.

Presented study shows similar behavior of the change of magnetic part of the entropy in quasi-binary $\mathrm{Ho}\left(\mathrm{Co}_{1-x} \mathrm{Fe}_{x}\right)_{2}$ compounds. Such behavior of magnetothermal properties of magnetic materials is very important from both practical and scientific points of view. In order to clarify unambiguously the role of substitute of base $\mathrm{Co}$ or $\mathrm{Ni}$ atoms by $\mathrm{Fe}$ in $\mathrm{R}\left(\mathrm{M}_{1-x} \mathrm{Fe}_{x}\right)_{2}$ intermetallic compounds with heavy Rare Earth elements, additional studies are required.

\section{Acknowledgments}

This work has been supported by the UrFU State contracts Nos. 2582 and 1362.

\section{References}

[1] A.E. Clark, Magnetostrictive $\mathrm{RFe}_{2}$ intermetallic compounds, Handbook on the Physics and Chemistry of Rare-Earth, Ed. K.A. Gschneider, North-Holland, Amsterdam 1979, p. 231.

[2] G.V. Brown, J. Appl. Phys.47, 3673 (1976).

[3] S.A. Nikitin, A.M. Tishin, Cryogenics 31, 166 (1991).

[4] A. Giguere, M. Foldeaki, W. Schnelle, E. Gmelin, J. Phys.: Cond. Matter 11, 6969 (1999).

[5] H. Wada, S. Tomekawa, M. Shiga, Cryogenics. 39, 915 (1999).

[6] H. Wada, Y. Tanabe, Appl. Phys. Lett. 79, 3302 (2001).

[7] D.H. Wang, H.D. Liu, S.L. Tang, S. Yang, S. Huang, Y. Du, Phys. Lett. A. 297, 247 (2002).

[8] N.H. Duc, A.D.T. Kim, J. Magn. Magn. Mater. 873, 242 (2002).

[9] N.K. Singh, S. Agarwal, K.G. Suresh, R. Nirmala, A.K. Nigam, S.K. Malik, Phys. Rev. B. 72, 014452 (2005).

[10] Niraj K. Singh, K.G. Suresh, D.S. Rana, A.K. Nigam, S.K. Malik, J. Phys.: Condens. Matter 18, 10775 (2006).

[11] X.B. Liu, Z. Altounian, J. App. Phys. 103, 07B304 (2008).

[12] M. Halder, S.M. Yusuf, M.D. Mukadam, K. Shashikala, Phys. Rev. B. 81, 174402 (2010).

[13] K.A. Gschneider, Jr., V.K. Pecharsky, Ann. Rev. Mater. Sci. 30, 387 (2000).

[14] S.K. Banerjee, Phys. Lett. 12, 16 (1964).

[15] Zou Jun-Ding, Shen Bao-Gen, Sun Ji-Rong, Chinese Phys. 16, 3843 (2007). 